\title{
Effects of different plant growth hormones on in vitro regeneration of a new Malaysian rice variety (Oryza Oryza sativa L. Var. MRIA 1. L. Var. MRIA 1) from stem explants
}

\author{
Nor Yasmin M. F. ${ }^{1,}{ }^{*}$, Norrizah J. S. ${ }^{2}$, Azani S. ${ }^{3}$ \\ 1, 2, 3 Faculty of Applied Sciences, Universiti Teknologi MARA (UiTM), Selangor Darul Ehsan, Malaysia
}

\section{Index Terms}

Oryza Sativa L. Var. MRIA 1

Plant Growth Regulators (PGR)

In Vitro Regeneration

Plant Tissue Culture

Received: 19 January 2016

Accepted: 12 July 2016

Published: 12 August 2016

\begin{abstract}
A study was conducted to determine the effects of different plant growth hormones towards in vitro regeneration of a new Malaysian Rice Variety (Oryza Oryza sativa L. Var. MRIA 1. L. Var. MRIA 1). Stem explants of 4-week-old aseptic seedlings were selected, and a total of 16 different combinations of NAA, IBA, BAP, and Kn were utilized. The most suitable plant growth hormones for in vitro regeneration of Oryza Oryza sativa L. var. MRIA 1. L. Var. MRIA 1 was obtained from MS (Murashige and Skoog) media supplemented with $1.0 \mathrm{mg} / \mathrm{l} \mathrm{NAA}$ and $0.5 \mathrm{mg} / \mathrm{l} \mathrm{Kn}$ with an average of $8.90 \pm 1.79$ number of shoots, $114.00 \pm 18.90$ number of roots, $10.70 \pm 2.62 \mathrm{~cm}$ length of shoots, and $8.70 \pm$ 1.64 number of leaves per explant. It was proved that the in vitro regeneration of Oryza Oryza sativa L. var. MRIA 1. L. Var. MRIA 1 from stem explants was achieved without entering the intermediate callus phase within four weeks of culture. Thus, laborious subculturing processes were not required to regenerate the multiple shoots. These findings provided an optimum plant growth hormone concentration for the tissue culture system of Oryza Oryza sativa L. var. MRIA 1. L. Var. MRIA 1. Acclimatization of regenerated plantlets of Oryza Oryza sativa L. var. MRIA 1. L. Var. MRIA 1 is recommended to serve as a complete in vitro regeneration protocol for the variety.
\end{abstract}

(C) 2016 The Author(s). Published by TAF Publishing.

\section{INTRODUCTION}

Rice is the most important crop in the world and it is a second most widely cultivated cereal in the world after wheat in which it is a staple food of over half the world's

\footnotetext{
*Corresponding author: Nor Yasmin M. F.

E-mail: noryasmin1412@gmail.com
}

population [1]. As in Malaysia, rice is the main food consumed by all the citizens. Many efforts have been done recently in order to improve the agronomic traits of rice through biotechnological techniques [2]. It is due to the rice improved by biotechnology have many advantages such as it is resistance towards geographical and seasonal destruction, produced in high yield and have good quality 
in terms of nutrition. Besides, the unique quality exhibits by the rice plant has been able to make it become the most common crop used in monocots plant studies. However, the successful rice transformation program and monocots studies require appropriate and reproducible cultivars that available throughout the years.

The MRIA 1 is the new variety of Oryza Oryza sativa $L$. Var. MRIA 1. L. produced by International Rice Research Institute (IRRI) through chemical mutation breeding [3]. This type of variety exhibit various kind of uniqueness including the short reproductive time, resistance towards seasonal and geographical fluctuation, and high mineral content compared to the current existing varieties. The Oryza Oryza sativa L. Var. MRIA 1. L. Var. MRIA 1 only takes 90 days to achieve reproductive phase in which it exhibit a short maturation period. Besides, it has $9.8 \%$ protein content compared to the current rice varieties which only have 6.3 to $7.1 \%$ [3]. Being one of an irrigated rice variety, the Oryza Oryza sativa L. Var. MRIA 1. L. Var. MRIA 1 have the ability to survive in a short water supply condition [3].

Owing to the fact that rice is an important monocots model in transformation system, plant tissue culture technique has been applied on rice as it ensures the continuous supply of rice within the countries However, the regeneration through callus induction normally led to somaclonal variation [4]. Therefore, direct in vitro regeneration is needed in order to produce multiple shoots without changing the genetic stability and avoid somaclonal variation.

Besides, the ability of the plant to be regenerated is genotype dependent and normally depends on explants and culture condition. Thus, the plant growth hormones play an important role for the regeneration capacity in Oryza Oryza sativa L. Var. MRIA 1. L. Var. MRIA 1. Previous study reported that the types and concentrations of plant growth hormones vary depending on the species and cultivars [5]. Therefore, this study was conducted to determine the effects of different plant growth hormones on in vitro regeneration of Oryza Oryza sativa L. Var. MRIA 1. L. Var. MRIA 1.

\section{MATERIALS AND METHODS}

\section{A. Plant Material and Seeds Sterilization}

The seeds of $f$ L. Var. MRIA 1 were obtained from Malaysian Agriculture Research and Development Institute (MARDI), Seberang Prai, Malaysia. The seeds were sterilised in $70 \%$ (v/v) Clorox with two drops of tween 20,
$50 \%, 40 \%, 30 \%, 20 \%$, and $10 \%$ Clorox followed by $70 \%$ ethanol for one minutes.

The seeds were then rinsed 3 times using sterile distilled water. The sterilized seeds were then cultured on MS media without supplementation of any plant growth hormones for 5 weeks to induce growth of aseptic seedlings.

\section{B. Media Preparation}

There were 4 types of regeneration media with different combinations and concentrations of Plant Growth Regulators (PGR) were prepared for in vitro regeneration. The $\mathrm{pH}$ of the media was adjusted to 5.8 prior to autoclaving by using $1 \mathrm{M} \mathrm{NaOH}$ and $1 \mathrm{M} \mathrm{HCl}$ [6]. The media were autoclaved at $121{ }^{\circ} \mathrm{C}$ for 20 minutes and allowed to be cooled for the usage.

\section{In Vitro Regeneration}

The stem explants ( $1 \mathrm{~cm}$ in length) of 5-week-old aseptic seedlings were cultured onto regeneration media. The cultures were incubated in relative humidity of $70-85 \%$, temperature $24 \pm 2^{\circ} \mathrm{C}$ and a photoperiod of $16 \mathrm{~h}$ in a photosynthetic photon flux density of 250-350 $\mu \mathrm{mol} \mathrm{m-2}$ s-1 [7]. The observations were made within 5 weeks of culture. All treatments were prepared in at least 10 replications.

\section{Determination of Growth Criteria for in Vitro Regeneration of Oryza Oryza sativa L. Var. MRIA 1. L. Var MRIA}

There were several parameters that have been recorded after 5 weeks in order to evaluate the ability of the explants of Oryza Oryza sativa L. Var. MRIA 1. Var. MRIA 1 to regenerate on the prepared regeneration media. The growth parameters used were the number of shoots, leaves, and roots, length of shoots, fresh weight and dry weight, and percentage of survival.

\section{E. Determination of Fresh Weight and Dry Weight}

The growth and development of regenerated plantlets were randomly sampled in term of their fresh and dry weight. After 5 weeks of culture period, the 5 samples were randomly taken out for evaluation of its fresh and dry weight.

The plants were taken out. The plants were then 
dried up using a piece of tissue before it is placed inside the oven at $50{ }^{\circ} \mathrm{C}$. The regenerated plantlets were weighed until constant weights were obtained.

\section{F. Statistical Analysis}

The statistical analysis used in this study was One-way ANOVA which was done using SPSS software version 21.0. Data collected was analyzed for any significance difference between treatments means $(p<0.05)$. All graphs were presented and plotted using Windows Excel.

\section{RESULTS AND DISCUSSION}

\section{A. Seeds Collection and Sterilization}

The seeds of Oryza Oryza sativa L. Var. MRIA 1. L. var. MRIA 1 were able to grow on MS-free hormone media (Figure 1). The germination rate was $95 \%$ to $99 \%$ after 4 weeks of culture. The results obtained indicated that an efficient sterilization technique and appropriate nutrient media were used throughout the culturing process.

Previous studies show that $70 \%$ Clorox is a suitable concentration for rice seeds sterilization compared to other concentrations since it prevents the browning and inhibition of seeds germination [8]. The seeds were soaked and shake vigorously in all the solutions to remove the microorganisms. This is the precaution steps in order to prevent contamination during the culturing system.

The Tween 20 was used to increase the effectiveness of the sterilization and as wetting agent which it helps to increase the surface contact with the detergent by reducing the surface tension of the seeds [9]. The prevention from contamination is an important thing in tissue culture system in order to ensure the survival of the plant cultured explant. It is due to the contamination is considered to be a majorfactor of losses during in vitro culture of plants [9].

\section{B. Number and Length of Shoots}

Statistical analysis done showed that there was a significant difference $(p<0.05)$ between the different concentrations of plant growth hormones on the number and length of shoots per explant (Figures $3 a$ and $3 b$ ). The results show that the number and length of shoots of Oryza Oryza sativa L. Var. MRIA 1. L. Var. MRIA 1 significantly affected by the combinations of plant growth hormones used.
Based on the Figure 3(a) the highest number of shoots produced was recorded in MS media supplemented with $1.0 \mathrm{mg} / \mathrm{l} \mathrm{NAA}$ and $0.5 \mathrm{mg} / \mathrm{l} \mathrm{Kn}(8.90 \pm 1.79$ mean number per explant), followed by MS media supplemented with $1.0 \mathrm{mg} / \mathrm{l} \mathrm{NAA}$ and $1.0 \mathrm{mg} / \mathrm{l} \mathrm{Kn}(8.70 \pm 3.13$ mean number per explant), $1.0 \mathrm{mg} / \mathrm{l} \mathrm{NAA}$ and $2.0 \mathrm{mg} / \mathrm{l} \mathrm{BAP} \mathrm{(8.40}$ \pm 2.95 mean number per explant), and $1.0 \mathrm{mg} / \mathrm{l} \mathrm{NAA}$ and

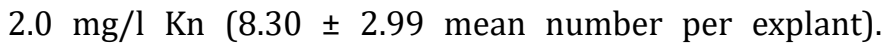
Meanwhile, the lowest number of shoots obtained from MS media supplemented with $1.0 \mathrm{mg} / \mathrm{L} \mathrm{IBA}$ and $1.0 \mathrm{mg} / \mathrm{L} \mathrm{BAP}$ (2.10 \pm 0.62 mean number per explant).

Meanwhile, both MS media supplemented with $1.0 \mathrm{mg} / \mathrm{l}$ $\mathrm{NAA}$ and $1.0 \mathrm{mg} / \mathrm{l} \mathrm{Kn}$ and $1.0 \mathrm{mg} / \mathrm{l} \mathrm{NAA}$ and $0.5 \mathrm{mg} / \mathrm{l} \mathrm{Kn}$ show a high significant length of shoots of Oryza Oryza sativa L. Var. MRIA 1. L. Var. MRIA 1 (Figure 3(b)). However, the highest length of shoots achieved by the treatment using MS media supplemented with 1.0 NAA and $1.0 \mathrm{Kn}$ which gave $11.70 \pm 2.19 \mathrm{~cm}$ mean length of shoots. The most unsuitable combination and concentration to induce longest shoots was observed in the MS media supplemented with $1.0 \mathrm{mg} / \mathrm{l} \mathrm{NAA}$ and $4.0 \mathrm{mg} / \mathrm{l}$ BAP.

All the number of shoots regenerated in most treatment increased as the concentration of cytokinin supplemented increased, except for the combination of IBA and BAP. Similar results were reported by Mahajam et al [10] which stated that the increasing concentration of BAP and Kn gave high number of shoots multiplication in rice (Oryza Oryza sativa L. Var. MRIA 1. L. var. Ranbir Basmati and Basmati 370).

It was stated from previous study that the different types of explants and genotype always results in the different optimal response towards cytokinin [10]. In this case, Kn was observed to be the best exogenous cytokinin required for in vitro regeneration of Oryza Oryza sativa $L$. Var. MRIA 1. L. Var. MRIA 1. In contrast, BAP was reported to be the most effective type of cytokinin for plant regeneration in rice Oryza Oryza sativa L. Var. MRIA 1. L. Var. MR219 [12]. In the present study, a low concentration of $\mathrm{Kn}(0.5 \mathrm{mg} / \mathrm{l})$ in combination with $1.0 \mathrm{mg} / \mathrm{l} \mathrm{NAA}$ gave the highest number of shoots per explant (Figure 2). However, high concentration of BAP and $\mathrm{Kn}(4 \mathrm{mg} / \mathrm{l})$ reduced the number of shoots regenerated. The results proved that low level of $\mathrm{Kn}$ in combination with NAA was the most optimum concentrations of plant growth hormones to induce formation of multiple shoots in Oryza Oryza sativa L. Var. MRIA 1. L. Var. MRIA 1.

As reported by the previous studies, the high concentration of Kn applied on in vitro regeneration media could give inhibitory effect of shoots multiplication 
in Chlorophytum borivilianum [13]. This fact supported the assumption made where the increasing concentration of $\mathrm{Kn}$ in the media might be toxic towards the regeneration of shoots in Oryza Oryza sativa L. Var. MRIA 1. L. Var. MRIA 1.

For the length of shoots, increasing concentration of cytokinin shows the declining length of shoots in all treatments. This results was corresponds with the results obtained for number of shoots and roots. Therefore, it can be concluded that the increasing concentrations of BAP and $\mathrm{Kn}$ in combinations with NAA or IBA were not suitable for regeneration of Oryza Oryza sativa L. Var. MRIA 1. L. Var. MRIA 1. Thus, high concentrations of cytokinin were not suitable to stimulate the cell elongation inshoots. As reported from the previous study, the supplementation of exogenous cytokinin above the optimal levels have caused the inhibitory impacts on shoots length and number [14].

It was previously stated that the regeneration ability depends on the ratio and concentrations of auxin and cytokinin supplied on the media [5]. In this study, the addition of $0.5 \mathrm{mg} / \mathrm{l} \mathrm{Kn}$ were successfully induced formation of longest shoots length. [15] stated that Kn promoted nutrients transportation from source to sink areas which eventually triggered the length of microshoots increments. As reported by [16], the compatible combination of cytokinin and auxin have proven to be crucial for shoots elongation involving many in vitro propagation. Similar to the current findings, which only certain plant growth hormone combinations are able to produce high number of shoots and length.

Besides, the length of shoots reflected the ability of the regenerated plantlets to elongate. It can be assumed that the effects of the cytokinin supplemented in the culture media has promoted the shoots multiplication and eventually increased the shoots length.

\section{Number of Roots}

Similar to the number of shoots, the highest number of roots was achieved in MS media supplemented with 1.0 $\mathrm{mg} / \mathrm{l} \mathrm{NAA}$ and $0.5 \mathrm{mg} / \mathrm{l} \mathrm{Kn} \mathrm{(114.00} \pm 18.90$ mean number per explant) as shown in Figure 3(c), followed by the MS media supplemented with $1.0 \mathrm{NAA} \mathrm{mg} / \mathrm{l} \mathrm{NAA}$ and 1.0 $\mathrm{mg} / \mathrm{l} \mathrm{Kn}(72.50 \pm 23.95$ mean number per explant $)$, and 1.0 $\mathrm{NAA}$ and $2.0 \mathrm{mg} / \mathrm{l} \mathrm{Kn}(20.20 \pm 4.10$ mean number per explant). The lowest number of roots obtained in the media supplemented with $1.0 \mathrm{mg} / \mathrm{l} \mathrm{IBA}$ and $2.0 \mathrm{mg} / \mathrm{l} \mathrm{BAP}$ ( $0.80 \pm 1.14$ mean number per explant).

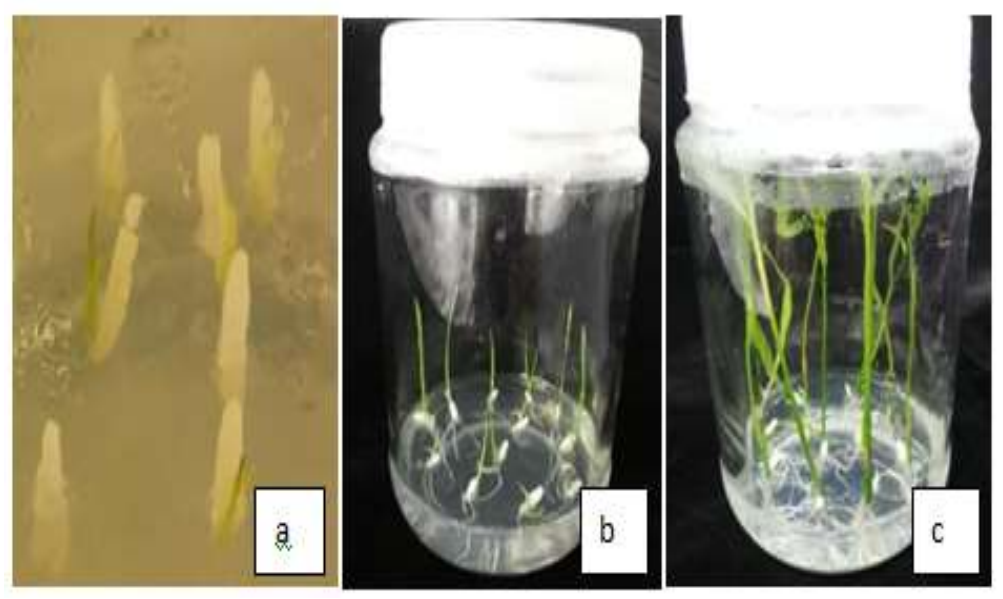






Fig. 1. The changes of seedlings development of Oryza Oryza sativa L. Var. MRIA 1. L. Var MRIA 1 within 4 weeks. (a) The growth of coleoptiles and radicles at the early 4 days culturing. The growth of seedlings after 1 weeks (b) 2 weeks (c) 3 weeks (d) and 4 weeks (e)

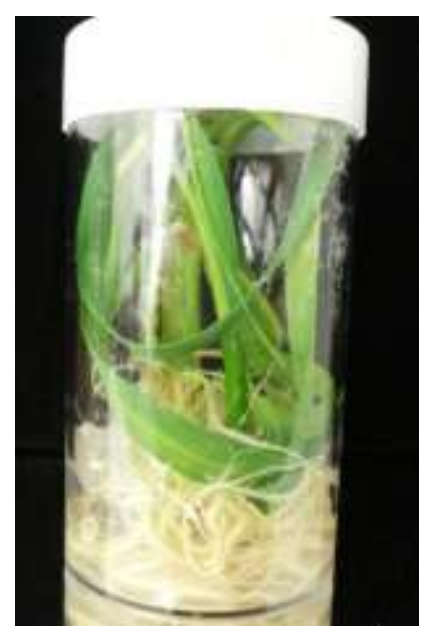

Fig. 2. The regenerated plantlets of Oryza Oryza sativa L. Var. MRIA 1. L. Var. MRIA 1 on MS media supplemented with $1.0 \mathrm{mg} / \mathrm{l} \mathrm{NAA}$ and $0.5 \mathrm{mg} / \mathrm{l} \mathrm{Kn}$ 


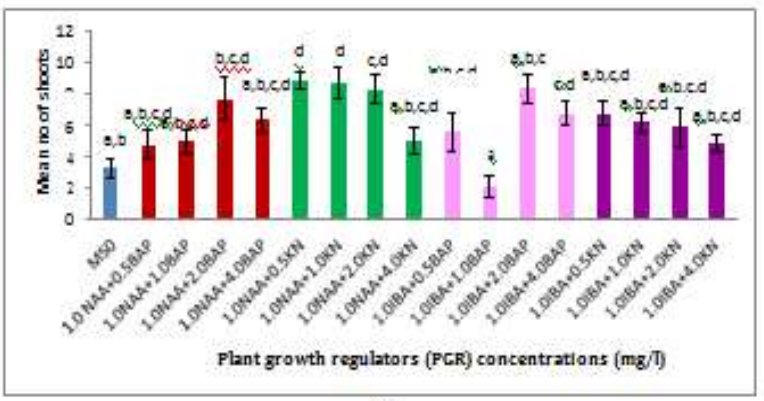

(a)

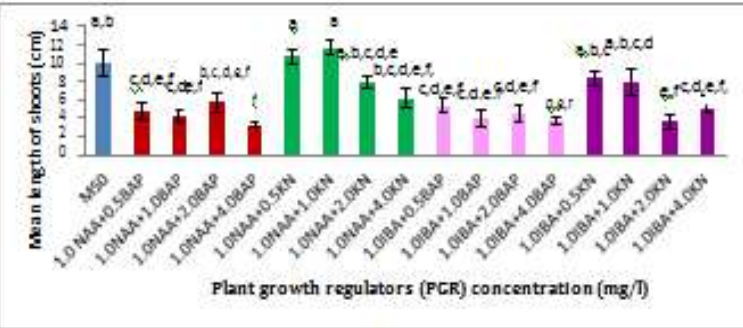

(b)

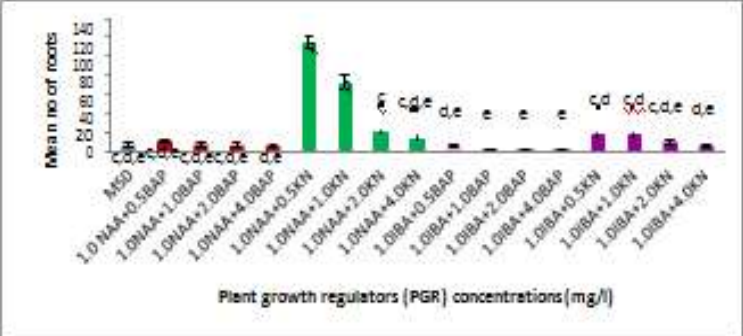

(c)

Fig. 3. The effects of different plant growth regulators on (a) Number of shoots. (b) Length of shoots and (b) Number of roots

For each concentration, the number of roots produced

prepared. The highest number of roots achieved in MS decreased as the concentration of BAP and Kn supplied increased. In addition, the combinations of IBA and BAP media supplemented with combination of IBA and BAP failed to produce high number of roots in all cultures was only $4.60 \pm 3.47$ mean number of roots per explant. 

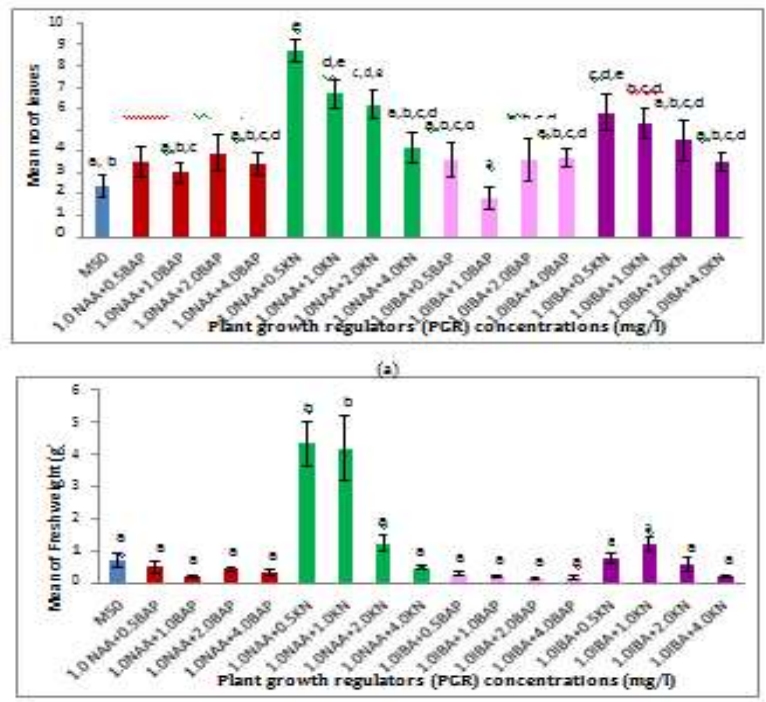

(b)

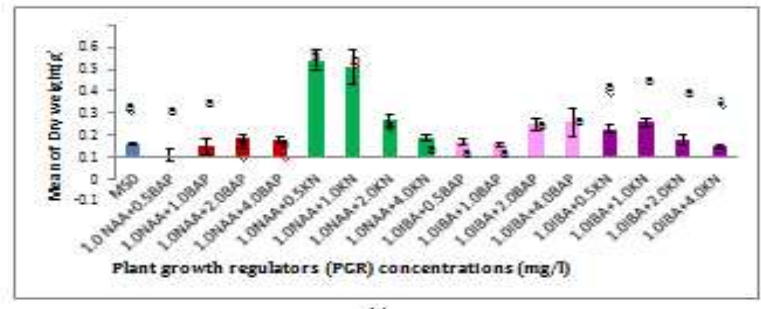

(c)

Fig. 4. The effects of different plant growth regulators on (a) Number of leaves. (b) Fresh weight. (c) Dry weight

MRIA 1. L Var. MRIA 1. However, it must be accompanied

The supplementation of $1.0 \mathrm{mg} / \mathrm{l} \mathrm{NAA}$ helps in promoting the initiations of roots from the explants since the highest number of roots was found better in the treatment with inclusions of NAA. Previous study done on $R$. graveolens L. species showed that the low concentration of auxin applied with combination of cytokinin enhanced root proliferation [17]. Similar to this study, a low concentration of auxin, $1.0 \mathrm{mg} / \mathrm{l}$ NAA with combination of $0.5 \mathrm{mg} / \mathrm{l} \mathrm{BAP}$ was able to produce high number of roots.

In addition, the supplemented of $0.5 \mathrm{mg} / \mathrm{l} \mathrm{Kn}$ helps the auxin to promote the growth of shoots and roots of Oryza Oryza sativa L. Var. MRIA 1. L. Var. MRIA 1. The results indicated that the combinations of NAA and Kn was compatible to induce regeneration of shoots and roots of Oryza Oryza sativa L. Var. MRIA 1. L. Var. MRIA 1. This fact supported by [5] which showed that

exogenous supplemented of auxin and cytokinin gave significant effect toward the shoots and roots formation from shoot apical meristem.

The results also proved that, even $1.0 \mathrm{mg} / \mathrm{l} \mathrm{NAA}$ was suitable for the regeneration of Oryza Oryza sativa L. Var. with the supplementation of exogenous cytokinin as well. In addition, supplementation of exogenous auxin is important in root development since it promotes the initiation of lateral roots in rice plant [18].

Roots initiation is a complex process which involves high concentration of auxin during the primodium initiation and low concentration of auxin during the primodium differentiation [16], [18], [19]. Based on this fact, it is suggested that $1.0 \mathrm{mg} / \mathrm{l}$ of NAA was enough to stimulate both initiation and differentiation of roots of Oryza Oryza sativa L. Var. MRIA 1. L. Var. MRIA 1.

In term of regeneration of roots, it is important to have an optimum concentration of auxin that can stimulate the best roots regenerations.

This is because roots are important parts of plant since it is a part that regulates the absorptions of water and nutrients [21] Previous study also have recorded that the application of exogenous auxin including NAA has been able to save the defect root hair elongation in the mutant rice [21]. Those facts and findings have been able to prove that the supplementation of auxin is important in promoting roots initiation and elongation of rice Oryza Oryza sativa L. Var. MRIA 1. L. Var. MRIA 1. 


\section{Number of Leaves}

Based on Figure 4 (a), the number of leaves regenerated from the stem explants were significantly affected by the different combinations and concentrations of hormones supplemented in the culture media $(\mathrm{P}<$ 0.05 ).

The highest number of leaves was obtained from the treatment using $1.0 \mathrm{mg} / \mathrm{l} \mathrm{NAA}$ and $0.5 \mathrm{mg} / \mathrm{l} \mathrm{Kn}(8.70 \pm$ 1.64 number of leaves per explant) followed by the treatment using $1.0 \mathrm{mg} / \mathrm{l} \mathrm{NAA}$ and $1.0 \mathrm{mg} / \mathrm{l} \mathrm{Kn} \mathrm{(6.70 \pm}$ 2.69 number of leaves per explant). MS media supplemented with $1.0 \mathrm{mg} / \mathrm{l} \mathrm{IBA}$ and $1.0 \mathrm{mg} / \mathrm{l} \mathrm{BAP}$ showed the lowest mean number of roots per explant (1.80 \pm 1.62$)$.

The combination of NAA and Kn also were proven to be the best for the formation of high number or leaves. However, increasing concentration of Kn supplemented to the media showed the declining number of leaves

As stated by [22] leaf is a part of plants that contain a great amount of photosynthetic tissues. Therefore, high number of leaves in the regenerated Oryza Oryza sativa L. Var. MRIA 1. L. Var MRIA 1 depicted high metabolic activities occur within the regenerated leaves.

This is because increasing number of leaves increased the number of stomata. It is well known that the stomata help in the regulations of gaseous exchange [23]. [24] has stated that cytokinin is important as a stomata regulator. It was reported that the application of $\mathrm{Kn}$ to isolated epidermis from Anthephora pubescens had caused a stomatal opening. The opening of stomata allowed the respiration and transpiration of the regenerated Oryza Oryza sativa L. Var. MRIA 1. L. Var. MRIA 1 to take place efficiently.

\section{E. Fresh and Dry Weight}

The results obtained for fresh and dry weight of in vitro regeneration plantlets were corresponding with the number of shoots, roots, leaves as well as length of shoots. The highest fresh weight $(4.35 \pm 1.57 \mathrm{~g}$ per explant) were obtained from the MS media treated with $1.0 \mathrm{mg} / \mathrm{L} \mathrm{NAA}$ with combination of $0.5 \mathrm{mg} / \mathrm{l} \mathrm{Kn}$, followed by $1.0 \mathrm{mg} / \mathrm{l}$ $\mathrm{NAA}$ and $1.0 \mathrm{mg} / \mathrm{l} \mathrm{Kn}(4.19 \pm 2.24 \mathrm{~g}$ per explant), and 1.0 $\mathrm{mg} / \mathrm{l} \mathrm{NAA}$ and $2.0 \mathrm{mg} / \mathrm{l} \mathrm{Kn}(1.26 \pm 0.57 \mathrm{~g}$ per explant) (Figure $4 \mathrm{~b}$ and $4 \mathrm{c}$ ).

Similar to the results of fresh weight, the highest dry weight also recorded from the treatment supplemented with $1.0 \mathrm{mg} / \mathrm{L}$ NAA with combination of $0.5 \mathrm{mg} / \mathrm{l} \mathrm{Kn}$
(0.44 $\pm 0.11 \mathrm{~g}$ per explant), followed by $1.0 \mathrm{mg} / \mathrm{l} \mathrm{NAA}$ and $1.0 \mathrm{mg} / \mathrm{l} \mathrm{Kn}(0.41 \pm 0.17 \mathrm{~g}$ per explant), and $1.0 \mathrm{mg} / \mathrm{l} \mathrm{IBA}$ and $2.0 \mathrm{mg} / \mathrm{l} \mathrm{Kn}(0.17 \pm 0.06 \mathrm{~g}$ per explant $)$.

These results indicated that the best regeneration medium yielded a regenerated plant that has comparatively high biomass. By referring to the results obtained for the fresh weight, the plant regenerated on 2.0 $\mathrm{mg} / \mathrm{l} \mathrm{NAA}$ and $0.5 \mathrm{mg} / \mathrm{l} \mathrm{Kn}$ have high amount of water content compared to the others. Measurement of fresh weight also essentials in order to measure the plant growth of the regenerated plants. As stated by North and Ndakidemi, [15] the weight of plant were used to measure the relatives growth and size of corresponding plants. Therefore, high fresh weight of regenerated rice Oryza Oryza sativa L. Var. MRIA 1. L. Var. MRIA 1 in this study showed that the best regeneration media yielded a high quality of regenerated plants with a high number of shoots and roots multiplications.

[25] stated that fresh and dry weight achieved due to accumulation of cytokinin which caused the stimulation of cell division and elongation by nutrient transportation. This stimulation eventually increased the quality of the regenerated plant in term of number of leaves, shoots, and shoots length. This fact supported the evidence that the size of plant determine its fresh weight and dry weight [16].

Fresh and dry weight act as a biomass indicator of the corresponding regenerated plants. Previous study done by [26] showed that a high roots biomass could help in the shoots development by supplying water and mineral nutrition for the shoots. This fact supported the findings that the most suitable regenerated media exhibit high fresh and dry weight which corresponded with their largest sizes and number of roots and shoots.

In addition, the application of cytokinins have been able to increase the number of shoots in orcid (Dendrobium nobile var. Emma white) which represents the importance of the exogenous cytokinin to promote the multiple shoots formation [27]. Similar to this study, the used of Kn has been able to produced plantlets of Oryza Oryza sativa L. Var. MRIA 1. L. Var. MRIA 1 with a high number of soots and roots.

\section{CONCLUSION}

The results obtained from thepresent study showed that direct regeneration of Oryza Oryza sativa L. Var. MRIA 1. L. Var. MRIA 1 without requiring the intermediate callus phase. It is successfully proved that 
the plant growth hormones supplied could induce the cell division and differentiation of the SAM of Oryza Oryza sativa L. Var. MRIA 1. L. Var. MRIA 1. In fact, exogenous PGR are required in order to promote mitotic activity and differentiation which could eventually stimulates the organogenesis in shoot apical meristem shoot apical meristem.

In addition, the regeneration without intermediate callus phase is important on order to produce high quality of plantlets without consuming long periods of time. This is because the callus induction is considered tedious steps which it require subculturing that is laborious and time consuming.

\section{ACKNOWLEDGEMENT}

The authors would like to thank to Malaysian Agriculture Research and Development Institute (MARDI), Seberang Prai, Malaysia for providing the Oryza Oryza sativa L. Var. MRIA 1. L. Var MRIA 1 seeds. The authors also would like to express their gratitude to Institute of Research Management and Innovation (IRMI), and University Technology Mara (UiTM). This work was funded by Ministry of Higher Education Malaysia under Fundamental Research Grant Scheme allocation with the grant number of FRGS/5/3(42/2012).

\section{REFERENCES}

[1] C. J. Yan and Q. H. Zhao, "Callus induction and plantlet regeneration from leaf blade of Oryza Oryza sativa $L$. Var. MRIA 1. L. Subsp. Indica," Plant Science Letters, vol. 25, no. 2, pp. 187-192, 1982. DOI: 10.1016/03044211(82)90176-6

[2] H. Wang, S. Taketa, A. Miyao, H. Hirochika and M. Ichii, "Isolation of a novel lateral-rootless mutant in rice (Oryza Oryza sativa L. Var. MRIA 1. L.) with reduced sensitivity to auxin," Plant Science, vol. 170, no. 1, pp. 70-77, 2006.

[3] S. Othman, Z. P. Hussain, C. C. Sheng, A. Man, R. Ahmad and B. Amzah, "Padi Aerob untuk mengatasi masalah kekurangan air," Jurnal Teknologi, vol. 70, no. 6, 2014.

[4] V. Girijashankar, "In vitro regeneration of Eucalyptus camaldulensis," Physiology and Molecular Biology of Plants, vol. 18, no. 1, pp. 79-87, 2012. DOI: 10.1007/s12298-011-0092-4

[5] L. Silvarajan, R. Nulit and F. R. Zaman, "Effects of plant growth regulators on in vitro regeneration of Malaysian indica rice (Oryza Oryza sativa L. Var. MRIA 1. L.) cv. MR219 by shoot apical meristem," Asian
Journal of Agricultural Reasearch, vol. 6, no. 4, pp. 180187, 2012. DOI: 10.3923/ajar.2012.180.187

[6] Y. Lin and Q. Zhang, "Optimising the tissue culture conditions for high efficiency transformation of indica rice," Plant Cell Reports, vol. 23, no. 8, pp. 540-547, 2005. DOI: $10.1007 / \mathrm{s} 00299-004-0843-6$

[7] M. R. Amirjani, "Effect of $\mathrm{NaCl}$ on some physiological parameters of rice," European Jurnal of Biology Sciences, vol. 3, no. 1, pp. 6-16, 2010.

[8] S. S. S. Naqvi, R. Sultana and H. Rasheed, "Tissue culture studies in Oryza Oryza sativa L. Var. MRIA 1. L. cvs. Basmati 385 and Super Basmati," Pakistan Journal of Botany, vol. 37, no. 4, pp. 823-828, 2005.

[9] O. BOyebanji, O. Nweke, O. Odebunmi, N. B. Galadima M. S. Idris, U. N. Nnodi, A. S. Afolabi and G. H Ogbadu, "Simple, effective and economical explants- surface sterilization protocol for cowpea, rice and sorghum seeds," African Journal of Biotech, vol. 8, no. 20, pp. 5395-5399, 2009.

[10] R. Mahajam, L. Aslam and H. Kousar, "Effect of growth regulators on in vitro cultures of two basmati rice genotypes: Ranbir basmati and Basmati 370," Journal of Pharmaceutical, Chemical and Biological Sciences, vol. 3, no. 4, pp. 1131-1138, 2013.

[11] J. Van Staden, E. Zazimalova and E. F. George, "Plant growth regulators II: Cytokinins, their Analogues and Antagonists," in Plant Propagation by Tissue Culture, 3rd ed., E. F George, M. A Hall, G. J. De Klerk, Eds. Dordrecht, Netherlands: Springer, 2008, p. 205226.

[12] N. N. Htwe, M. Maziah, H. C. Ling, F. Q. Zaman and A. M. Zain, "Responses of some selected Malaysian rice genotypes to callus induction under in vitro salt stress," African Journal of Biotechnology, vol. 10, no. 3, pp. 350-362, 2011.

[13] M. F. Ashraf, M. A. Aziz, N. Kemat and I. Ismail, "Effect of cytokinin types, concentrations and their interactions on in vitro shoot regeneration of Chlorophytum borivilianum Sant. and Fernandez," Electronic Journal of Biotechnology, vol. 17, no. 6, pp. 275-279, 2014. DOI: 10.1016/j.ejbt.2014.08.004

[14] J. Roy and N. Banerjee, "Induction of callus and plant regeneration from shoot tip explants of Dendrobium fimbriatum Lindl. var. oculatum Hk. f.," Scientia Horticulturae, vol. 97, no. 3, pp. 333-340, 2003.

[15] M. H. T. Sirchi, M. A. Kadir, M. A. Aziz, P. A. A Rashid, A. Rafat and M. B. Javadi, "Plant regeneration as affected by Plant Growth Regulators (PGR) in mangosteen 
(Garcinia mangostana L.)," African Journal of Biotechnology, vol. 7, no. 15, pp. 2693-2701, 2008.

[16] J. J. North and P. A. Ndakidemi, "Evaluation of different ratios of auxin and cytokinin for the in vitro propagation of Streptocarpus rexii Lindl," International Journal of Physical Sciences, vol. 7, no. 7, pp. 1083-1087, 2012.

[17] S. Bohidar, M. Thirunavoukkarasu and T. V. Roa, "Effect of plant growth regulators on in vitro micropropagation of Garden Rue (R. graveolens L.)," International Journal of Integrative Biology, vol. 3, no. 1, pp. 36-43, 2008.

[18] V. Sreevidya, R. J. Hernandez-Oane, P. Gyaneshwar, Lara-Flores, J. K. Ladha and P. M. Reddy, "Changes in auxin distribution patterns during lateral root development in rice," Plant Science, vol. 178, no. 6, pp. 531-538, 2010. DOI: 10.1016/j.plantsci.2010.03.004

[19] A. Pelosi, M. C. S. Lee, S. F. Chandler and J. D. Hamill, "Hormonal control of root primordial differentiation and root formation in cultured explants of Eucalyptus globulus seedlings," Functional Plant Biology, vol. 22, no. 3, pp. 409-415, 1995.

[20] I. M. Sussex, J. A. Godoy, N. M. Kerk, M. J. Laskowski, H. C. Nusbaum, J. A. Welsch and M. E. Williams, "Cellular and molecular events in a newly organizing lateral root meristem," Philosophical Transactions of the Royal Society of London B: Biological Sciences, vol. 350, no. 1331, pp. 39-43, 1995.

[21] B. R. Debi, J. Mushika, S. Taketa, A. Miyao, H. Hirochika and M. Ichii, "Isolation and characterization of a short lateral root mutant in rice (Oryza Oryza sativa L. Var.
MRIA 1. L.)," Plant Science, vol. 165, no. 4, pp. 895-903, 2003. DOI: $10.1016 / S 0168-9452(03) 00293-0$

[22] G. C. Evans, The Quantitative Analysis of Plant Growth. Oxford, UK: Oxford Press, 1982.

[23] R. O. Knight, The Plant in Relation to Water, 2nd ed. London, UK: Heinemann Educational Books Ltd, 1967.

[24] W. J. Davies and T. A. Mansfield, "Auxins and stomata," in Stomatal Function, E. Zeiger, G. D. Farquhar and I. R. Cowan, Eds. Stanford, CA: Stanford University Press, 1987, pp. 293-309.

[25] L. E. P. Peres, N. Majerowicz and E. G. B. Kerbauy, "Dry matter partitioning differences between shoots and roots in two contrasting genotypes of orchids and their relationship witth endogenous levels of auxins, cytokinins and abscisic acid," Revista Brasileira de Fisiologia Vegetal, vol. 13, no. 2, pp. 185-195, 2001. DOI: $10.1590 / \mathrm{S} 0103-31312001000200007$

[26] C. Chen, M. Huang, K. Lin, S. Wong, W. Huang and C. Yang, "Effects of light quality on the growth, development and metabolism of rice seedling (Oryza Oryza sativa L. Var. MRIA 1. L.)," Research Journal of Biotechnology, vol. 9, no. 4, pp. 15-24, 2014.

[27] S. Asghar, T. Ahmad, A. H. Ishfaq and M. Yaseen, "In vitro propagation of orchid (Dendrobium nobile) var. Emma white," African Journal of Biotechnology, vol. 10, no. 16, pp. 3097-3103, 2011. DOI: 10.5897/AJB10.401

[28] M. Valizadeh, S. K. K. Tabar and G. A. Nematzadeh, "Effect of plant growth regulators and callus induction and regeneration of cumin (Cuminum cyminum)," Indian Journal of Crop Science, vol. 2, no. 2, pp. 287290, 2007. 